\title{
REVIEW
}

\section{DNA methylation of the BDNF gene and its relevance to psychiatric disorders}

\author{
Tempei Ikegame ${ }^{1,2}$, Miki Bundo ${ }^{1}$, Yui Murata ${ }^{1,2}$, Kiyoto Kasai ${ }^{2}$, Tadafumi Kato ${ }^{3}$ and Kazuya Iwamoto ${ }^{1,4}$ \\ Brain-derived neurotrophic factor (BDNF) is a neurotrophic factor, which is important for neuronal survival, development and \\ synaptic plasticity. Accumulating evidence suggests that epigenetic modifications of $B D N F$ are associated with the \\ pathophysiology of psychiatric disorders, such as schizophrenia and mood disorders. Patients with psychiatric disorders \\ generally show decreased neural BDNF levels, which are often associated with increased DNA methylation at the specific BDNF \\ promoters. Importantly, observed DNA methylation changes are consistent across tissues including brain and peripheral blood, \\ which suggests potential usefulness of these findings as a biomarker of psychiatric disorders. Here we review DNA methylation \\ characteristics of $B D N F$ promoters of cellular, animal and clinical samples and discuss future perspectives. \\ Journal of Human Genetics (2013) 58, 434-438; doi:10.1038/jhg.2013.65; published online 6 June 2013
}

Keywords: Epigenetics; peripheral blood; postmortem brain; schizophrenia

\section{INTRODUCTION}

Neurotrophic factors are known to be important regulators of neural survival, development, function and plasticity in central and peripheral nervous system. To date, nerve growth factor, neurotrophin-3 (NT-3), NT- $4 / 5$ and brain-derived neurotrophic factor (BDNF) have been characterized as members of neurotrophic factors. Among them, BDNF was purified and cloned in 1982 as the second member. Subsequent studies revealed that BDNF is a unique activity-dependent NT widely expressed in the brain and has long-term effects on neuronal survival, development and synaptic plasticity. Further studies showed that BDNF may be involved in the pathophysiology of a wide range of psychiatric disorders, such as schizophrenia, major depression and bipolar disorder. Of note, accumulating evidence suggests that epigenetic modifications that include DNA methylation of BDNF promoters are clearly associated with the pathophysiology of psychiatric disorders. In this paper, we review the findings on DNA methylation of $B D N F$ promoters in cellular, animal and clinical studies and discuss future perspectives.

\section{REGULATION AND FUNCTION OF BDNF}

Rodent and human $B D N F$ has a characteristic gene structure, consisting of multiple untranslated exons $(\geqslant 8)$ and a single coding $\operatorname{exon}^{1-6}$ (Figure 1). The untranslated exons contain separate promoters upstream of each exon. The coding exon encodes pro-BDNF protein as well as $5^{\prime}$ and $3^{\prime}$ untranslated regions. ${ }^{6}$ The $3^{\prime}$ untranslated region of the coding exon also contains two polyadenylation sites. Expression of $B D N F$ gene is spatiotemporally regulated by these different promoters and polyadenylation sites, yielding approximately 34 alternative splicing transcripts. ${ }^{78}$ In addition, the BDNF-AS (BDNF antisense RNA), which gives rise to non-coding RNA to form dsRNA duplexes with $B D N F$ mRNA in vivo, may further make the $B D N F$ regulation complex. ${ }^{4,7} B D N F$ is widely expressed throughout the brain, including the frontal cortex, hippocampus, amygdala, corpus callosum, basal ganglia, thalamus, brainstem, pons and cerebellum. ${ }^{7,9,10}$ Regardless of the type of splice variants, all mRNAs are translated into single proBDNF proteins. The pro-BDNF protein is then cleaved into a mature form of BDNF by different enzymes, including furin within the endoplasmic reticulum, proconvertases enzymes within secretory vesicles and tissue plasminogen activator/plasmin in the extracellular space. ${ }^{11}$ The amino-acid sequence of the mature human BDNF is identical to that of porcine, rat and mouse, ${ }^{12,13}$ and is $90 \%$ identical to fish $\mathrm{BDNF}{ }^{14}$ indicating that the $\mathrm{BDNF}$ gene is highly conserved during vertebrate evolution.

Mature BDNF protein is secreted as a basic protein that can bind to two distinct transmembrane receptors, $\mathrm{p} 75 \mathrm{NT}$ receptor $\left(\mathrm{p} 75^{\mathrm{NTR}}\right)$ and TrkB. ${ }^{15,16}$ Binding of BDNF to TrkB leads to phosphorylation of tyrosine residues in the subcellular domain of the $\operatorname{TrkB}$ and activates downstream signal cascades that are essential for neural differentiation and survival, neurite outgrowth and synaptic plasticity. ${ }^{16}$ On the other hand, pro-BDNF preferentially binds to $\mathrm{p} 75^{\mathrm{NTR}}$ and induces neuronal apoptosis and hippocampal long-term depression. ${ }^{17-19}$

The importance of BDNF in neural development and survival is confirmed by animal studies. Most of homozygous $B d n f$ mutant mice die within 2 days after birth, but some survive for 2-4 weeks. They show striking behavioral phenotypes of spinning, head bobbing and hindlimb extension, with deficiencies in coordination of movements

${ }^{1}$ Department of Molecular Psychiatry, Graduate School of Medicine, The University of Tokyo, Tokyo, Japan; ${ }^{2}$ Department of Neuropsychiatry, Graduate School of Medicine, The University of Tokyo, Tokyo, Japan; ${ }^{3}$ Laboratory for Molecular Dynamics of Mental Disorders, RIKEN Brain Science Institute, Wako-city, Saitama, Japan and ${ }^{4}$ PRESTO, Japan Science and Technology Agency, Kawaguchi-shi, Saitama, Japan

Correspondence: Dr K Iwamoto, Department of Molecular Psychiatry, Graduate School of Medicine, The University of Tokyo, 7-3-1 Hongo, Bunkyo-ku, Tokyo 113-8655, Japan. E-mail: kaziwamoto-tky@umin.ac.jp

Received 29 April 2013; revised 7 May 2013; accepted 11 May 2013; published online 6 June 2013 


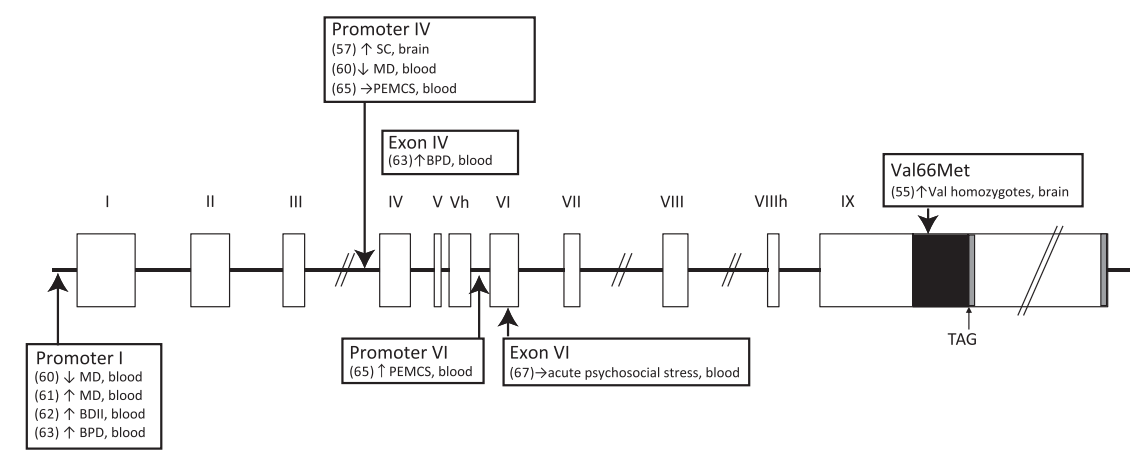

Figure 1 Structure and DNA methylation studies of the human BDNF gene. Exons are represented as boxes and the introns as lines. The roman numerals indicate the numbers of exons. The black box represents the pro-BDNF protein. Two gray boxes in exon IX are the polyadenylation sites. BDII, bipolar disorder II; BPD, borderline personality disorder; MD, major depression; PEMCS, prenatal exposure to maternal cigarette smoking; SC, suicide completers. Direction of DNA methylation changes are indicated by arrows.

and balance. Interestingly, structural abnormalities of central nervous system in Bdnf mutant mice are relatively mild, although $B d n f$ influences the development of the cortex, hippocampus, midbrain, cerebellum and structures in other brain regions. ${ }^{20}$

\section{POSSIBLE ROLES OF BDNF IN MENTAL DISORDERS}

The human $B D N F$ gene is located on chromosome $11 \mathrm{p} 13 .^{21,22}$ The Val66Met polymorphism (rs6265) in the BDNF gene is associated with the intracellular trafficking and processing of pro-BDNF protein. $^{23}$ A meta-analysis of case-control studies confirmed that this polymorphism had association with the risk of schizophrenia and other mental disorders, such as substance-related disorders and eating disorders. ${ }^{24}$ This analysis demonstrated that individuals with the Met/Met homozygous allele showed a 19\% higher risk of developing schizophrenia and other psychotic disorders than those with the Val/Met heterozygotes. Though initial magnetic resonance imaging studies showed that individuals with Met allele have smaller volumes of the frontal gray matter and hippocampus, and larger CSF volume than Val homozygotes, ${ }^{25}$ it is cautioned that such finding might be subject to publication bias. ${ }^{26}$

Postmortem studies generally reveal the downregulation of BDNF expression in patients with schizophrenia and mood disorders. In schizophrenia, expression levels of BDNF in the prefrontal cortex, parietal cortex and hippocampus were decreased. ${ }^{27-30}$ However, some early studies reported increased BDNF levels in the brains of patients with schizophrenia. ${ }^{31-33}$ In patients with bipolar disorder, decreased BDNF levels are reported in the frontal cortex and hippocampal CA4 region, compared with controls. ${ }^{34-36}$

Using the peripheral blood, a large number of clinical studies have been conducted to examine the relationship between BDNF levels and diagnosis. In major depression, several meta-analysis indicated that serum BDNF level is significantly decreased in patients. ${ }^{37-39}$ In schizophrenia, a significant reduction of serum BDNF level was also reported in both first-episode patients (patients who had experienced a first acute psychosis) and chronic-medicated patients (patients suffering from schizophrenia for a long term), compared with healthy controls. ${ }^{40}$ Recent meta-analysis further demonstrated that serum BDNF level was reduced in both medicated and drug-free patients with schizophrenia regardless of medication dosage. ${ }^{41}$

\section{DNA METHYLATION OF BDNF: CELLULAR AND ANIMAL MODELS}

The importance of DNA methylation in the regulation of Bdnf expression was firstly identified in the experiments using cultured rat neurons. ${ }^{42,43}$ Membrane depolarization artificially induced by potassium chloride led to a decrease of DNA methylation at promoter IV and an increase of transcription from this promoter. Subsequent studies demonstrated that membrane depolarization decreased expression levels of Dnmt1 and Dnmt3a in cultured mouse cortical neurons and concomitantly decreased DNA methylation levels at the promoters I and IV. ${ }^{44,45}$ Similarly, 5-aza-2deoxycytidine, a DNA methyltransferase inhibitor, induced demethylation at $B d n f$ promoter I in mouse Neuro-2a cells. This demethylation was associated with upregulation of $B d n f$ gene expression. ${ }^{46}$

In animal models, infusion of zebularine, another DNA methyltransferase inhibitor, to the rat hippocampus CA1 region significantly decreased DNA methylation levels at promoters I, IV and VI. Expressions from these promoters are concomitantly increased ${ }^{47}$ In serotonin transporter knock-out rats, increased DNA methylation at promoter IV and downregulation of gene expression from this promoter has been reported. ${ }^{48}$ A similar correlation has been observed in chicken. A study reported that the expression levels of two alternative splicing variants of chicken BDNF: cBDNF 1 and 2 were negatively regulated by the DNA methylation levels in their promoters. ${ }^{49}$ These results suggested that the correlation between DNA methylation and gene expression of BDNF gene in the brain is well conserved during vertebrate evolution.

Various environmental stimuli can affect the epigenetic status of Bdnf gene. ${ }^{50}$ For example, both Bdnf mRNA and protein levels in the visual cortex of adult rats, which were reared under light-deprivation condition, were significantly decreased, and they were associated with increased DNA methylation level at $B d n f$ promoter IV. ${ }^{51}$ Male mice born from methylmerculy-exposed mother showed a significant decrease of $B d n f$ in the dentate gyrus with a significant increase in DNA methylation at $B d n f$ promoter IV. ${ }^{52}$ Psychosocial stress such as early-life stress and post-traumatic stress also induced downregulation of exon IV mRNA and increase of DNA methylation in the prefrontal cortex and hippocampus. ${ }^{53,54}$

\section{DNA METHYLATION OF BDNF IN THE POSTMORTEM BRAIN TISSUES OF PATIENTS WITH PSYCHIATRIC DISORDERS}

DNA methylation studies of BDNF promoters using human brain and blood samples are summarized in Figure 1 and Table 1 . In the prefrontal cortex, subjects with Val/Val homozygote for Val66Met polymorphism showed a higher DNA methylation level compared with Met carriers in the vicinity of SNP site (average methylation level was $83 \%$ for $\mathrm{Val} / \mathrm{Val}$ and $78 \%$ for Met carriers). ${ }^{55}$ Another study revealed that DNA methylation level of the promoter region of BDNF 


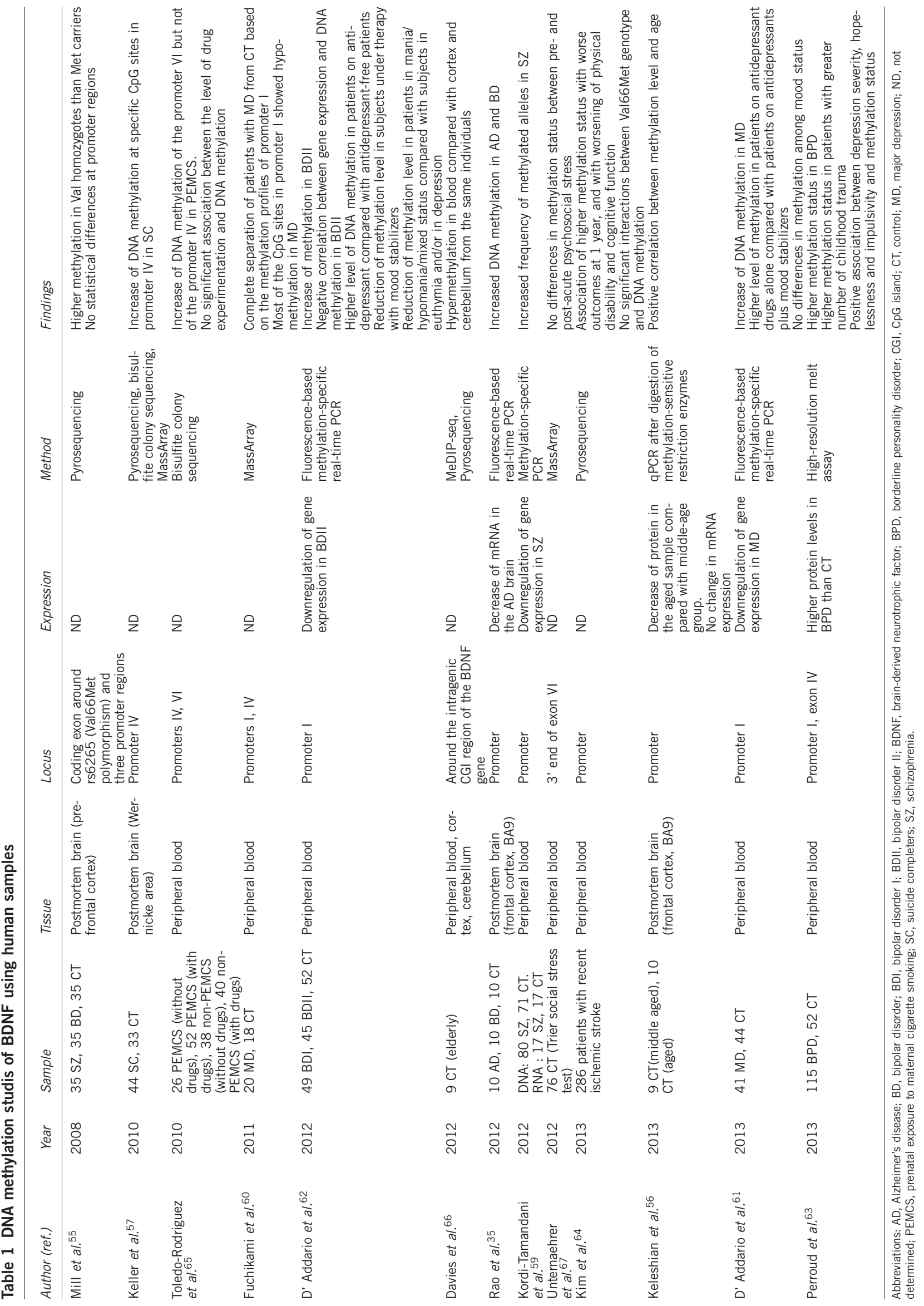


was associated with age, and BDNF protein level was significantly decreased in the prefrontal cortex of elderly people. ${ }^{56}$

In psychiatric disorders, DNA methylation levels of BDNF-coding exon and three different promoter regions in the prefrontal cortex of patients with bipolar disorder or schizophrenia were examined by pyrosequencing. ${ }^{55}$ However, both diseases did not show statistical DNA methylation differences compared with control subjects. On the other hand, one study reported significantly higher DNA methylation of $B D N F$ in the prefrontal cortex of patients with bipolar disorder and those with Alzheimer's disease. ${ }^{35}$ Significant increase of DNA methylation was also reported in the Wernicke area of suicide completers. At the promoter IV region, four $\mathrm{CpG}$ sites showed increased DNA methylation in suicide completers (average methylation level was about 5\% for controls and $11 \%$ for suicide completers). Higher DNA methylation was generally associated with lower expression levels of BDNF mRNA in this study. The same research group also reported no alteration of the DNA methylation status of TRKB promoter. ${ }^{57,58}$

\section{DNA METHYLATION OF BDNF IN THE PERIPHERAL BLOOD TISSUES OF PATIENTS WITH PSYCHIATRIC DISORDERS}

In schizophrenia, one study assessed DNA methylation level of BDNF by methylation-specific PCR. Patients had more methylated alleles compared with control subjects and showed downregulation of $B D N F^{59}$ In major depression, DNA methylation levels of BDNF promoters I and IV have extensively been examined. DNA methylation levels of 29 out of $35 \mathrm{CpG}$ units in BDNF promoter I of patients were significantly different from those of controls. ${ }^{60}$ Notably, most of the CpG units showed hypomethylation in depressed patients compared with those in controls in this study. By contrast, D'Addario et al. ${ }^{61}$ detected significant hypermethylation at $B D N F$ promoter I in major depression by quantitative methylationspecific PCR procedure (about 32\% for patients and $24 \%$ for controls). They further reported that DNA methylation level was significantly lower in patients treated with mood stabilizers. In bipolar disorder, the same group reported hypermethylation of the BDNF promoter I region in patients with bipolar disorder II, which is a form of bipolar disorder exhibiting a less intense manic episode (about 33\% for patients and $24 \%$ for controls), but not in those with typical bipolar disorder (about 20\%). Similarly to the previous report, patients treated with mood stabilizers showed lower DNA methylation level than those treated with other drugs. ${ }^{62}$ Hypermethylations at promoters I and IV were also detected in patients with borderline personality disorder by using high-resolution melt analysis. ${ }^{63}$ There was a significant positive association between depression severity, hopelessness, impulsivity and child trauma and BDNF methylation level. However, no association was found between BDNF protein levels and DNA methylation levels in this study. Another study regarding poststroke depression suggested that higher methylation level at BDNF promoter I was associated with incident poststroke depression and worsening of depressive symptoms over the 1-year follow-up. ${ }^{64}$

\section{CONCLUSIONS AND PERSPECTIVES}

Cellular and animal models clearly suggest that expression of $B d n f$ in neuronal cells is tightly regulated by DNA methylation of specific promoters. DNA methylation status of promoters I and IV was extensively studied, and they were found to be tightly regulated in the physiological condition. In response to environmental stimuli, methylation levels of these promoters can be actively increased or decreased and transcription from these promoters is altered accordingly. Whereas decreased DNA methylation level involves dissociation of $\mathrm{MeCP} 2$ from the promoter, the mechanism of increased DNA methylation at the specific sites remains largely unclear. In the human sample, aging and genotype affect the methylation status of BDNF promoters. In general, in the various psychiatric conditions, patients show decreased BDNF levels in the brain and in peripheral blood. In the examined cases, decreased BDNF levels were often associated with increased DNA methylation at the BDNF promoters. Very importantly, consistent DNA methylation difference was observed between brain and peripheral blood samples. Considering the advantage of peripheral samples over the postmortem brains in terms of accessibility and longitudinal traceability, in addition to pursuing the pathophysiology of psychiatric disorders, DNA methylation status of $B D N F$ promoters in blood samples will be useful for developing biomarkers. Currently, increased DNA methylation of BDNF promoter has been identified in a wide range of psychiatric disorders. Defining the precise environmental factors that affect DNA methylation levels in patients will be needed. In addition, effect of the severity of disease, disease duration and effects of medication should also be thoroughly tested. Molecular mechanisms of altering DNA methylation levels at specific BDNF promoter sites will be further pursued using cellular and animal models.

\section{ACKNOWLEDGEMENTS}

This work was partly supported by funding for research (development of biomarker candidates for social behavior) carried out under the Strategic Research Program for Brain Sciences (to KK) and by Grant-in-Aid for Scientific Research on Innovative Areas (unraveling the micro-endophenotypes of psychiatric disorders at the molecular, cellular and circuit levels; to TK and KI) from the Ministry of Education, Culture, Sports, Science and Technology of Japan and by JST, CREST (to TK).

1 Timmusk, T., Palm, K., Metsis, M., Reintam, T., Paalme, V., Saarma, M. et al. Multiple promoters direct tissue-specific expression of the rat BDNF gene. Neuron 10, 475-489 (1993)

2 Aoyama, M., Asai, K., Shishikura, T., Kawamoto, T., Miyachi, T., Yokoi, T. et al. Human neuroblastomas with unfavorable biologies express high levels of brain-derived neurotrophic factor mRNA and a variety of its variants. Cancer Lett. 164, 51-60 (2001).

3 Marini, A. M., Jiang, X., Wu, X., Tian, F., Zhu, D., Okagaki, P. et al. Role of brain-derived neurotrophic factor and NF- $\mathrm{\kappa B}$ in neuronal plasticity and survival-from genes to phenotype. Restor. Neurol. Neurosci. 22, 121-130 (2004)

4 Liu, Q.-R., Walther, D., Drgon, T., Polesskaya, O., Lesnick, T. G., Strain, K. J. et al. Human brain derived neurotrophic factor (BDNF) genes, splicing patterns, and assessments of associations with substance abuse and Parkinson's Disease. Am. J. Med. Genet. B. Neuropsychiatr. Genet. 134B, 93-103 (2005).

5 Liu, Q. R., Lu, L., Zhu, X. G., Gong, J. P., Shaham, Y. \& Uhl, G. R. Rodent BDNF genes, novel promoters, novel splice variants, and regulation by cocaine. Brain Res. 1067, 1-12 (2006).

6 Aid, T., Kazantseva, A., Piirsoo, M., Palm, K. \& Timmusk, T. Mouse and rat BDNF gene structure and expression revisited. J. Neurosci. Res. 85, 525-535 (2007).

7 Pruunsild, P., Kazantseva, A., Aid, T., Palm, K. \& Timmusk, T. Dissecting the human BDNF locus: bidirectional transcription, complex splicing, and multiple promoters. Genomics 90, 397-406 (2007).

8 Baj, G. \& Tongiorgi, E. BDNF splice variants from the second promoter cluster support cell survival of differentiated neuroblastoma upon cytotoxic stress. J. Cell. Sci. 122 36-43 (2009)

9 Murer, M. G., Boissiere, F., Yan, Q., Hunot, S., Villares, J., Faucheux, B. et al. An immunohistochemical study of the distribution of brain-derived neurotrophic factor in the adult human brain, with particular reference to Alzheimer's disease. Neuroscience 88, 1015-1032 (1999).

10 Murer, M. G., Yan, Q. \& Raisman-Vozari, R. Brain-derived neurotrophic factor in the control human brain, and in Alzheimer's disease and Parkinson's disease. Prog. Neurobiol. 63, 71-124 (2001).

11 Barker, P. A. Whither proBDNF? Nat. Neurosci. 12, 105-106 (2009).

12 Hofer, M., Pagliusi, S. R., Hohn, A., Leibrock, J. \& Barde, Y. A. Regional distribution of brain-derived neurotrophic factor mRNA intheadultmouse brain. EMBO J. 9, 2459-2464 (1990).

13 Rosenthal, A., Goeddel, D. V., Nguyen, T., Martin, E., Burton, L. E. Shih, A et al. Primary structure and biological activity of human brain-derived neurotrophic factor. Endocrinology 129, 1289-1294 (1991). 
14 Götz, R., Raulf, F. \& Schartl, M. Brain-derived neurotrophic factor is more highly conserved in structure and function than nerve growth factor during vertebrate evolution. J. Neurochem. 59, 432-442 (1992).

15 Dechant, G. \& Barde, Y. A. The neurotrophin receptor p75NTR novel functions and implications for diseases of the nervous system. Nat. Neurosci. 5, 1131-1136 (2002)

16 Huang, E. J. \& Reichardt, L. F. Trk receptors: roles in neuronal signal transduction. Annu. Rev. Biochem. 72, 609-642 (2003).

17 Bibel, M., Hoppe, E. \& Barde, Y. a. Biochemical and functional interactions between the neurotrophin receptors trk and p75NTR. EMBO J. 18, 616-622 (1999).

18 Teng, H. K., Teng, K. K., Lee, R., Wright, S., Tevar, S., Almeida, R. D. et al. ProBDNF induces neuronal apoptosis via activation of a receptor complex of p75NTR and sortilin. J. Neurosci. 25, 5455-5463 (2005).

19 Woo, N. H., Teng, H. K., Siao, C.-J., Chiaruttini, C., Pang, P. T., Milner, T. A. et al. Activation of p75NTR by proBDNF facilitates hippocampal long-term depression. Nat. Neurosci. 8, 1069-1077 (2005).

20 Kucera, J. A. N., Lee, K. F., Loring, J. \& Jaenisch, R. Studies on the physiological role of brain-derived neurotrophic factor and neurotrophin-3 in knockout mice. Int. J. Dev. Biol. 39, 799-807 (1995).

21 Maisonpierre, P. C., Le Beau, M. M., Espinosa, R. 3rd., Ip, N. Y., Belluscio, L., de la Monte, S. M. et al. Human and rat brain-derived neurotrophic factor and neurotrophin-3: gene structures, distributions, and chromosomal localizations. Genomics 10, 558-568 (1991).

22 Ozçelik, T., Rosenthal, A. \& Francke, U. Chromosomal mapping of brain-derived neurotrophic factor and neurotrophin-3 genes in man and mouse. Genomics 10, 569 575 (1991).

23 Chen, Z. Y., Patel, P. D., Sant, G., Meng, C. X., Teng, K. K., Hempstead, B. L. et al. Variant brain-derived neurotrophic factor (BDNF) (Met66) alters the intracellula trafficking and activity-dependent secretion of wild-type BDNF in neurosecretory cells and cortical neurons. J. Neurosci. 24, 4401-4411 (2004).

24 Gratacos, M., Gonzalez, J. R., Mercader, J. M., de Cid, R., Urretavizcaya, M. \& Estivill, X. Brain-derived neurotrophic factor Val66Met and psychiatric disorders: meta-analysis of case-control studies confirm association to substance-related disorders, eating disorders, and schizophrenia. Biol. Psychiatry 61, 911-922 (2007)

25 Szeszko, P. R., Lipsky, R., Mentschel, C., Robinson, D., Gunduz-Bruce, H., Sevy, S. et al. Brain-derived neurotrophic factor Val66met polymorphism and volume of the hippocampal formation. Mol. Psychiatry 10, 631-636 (2005).

26 Molendijk, M. L., Bus, B. A., Spinhoven, P., Kaimatzoglou, A., Oude Voshaar, R. C., Penninx, B. W. et al. A systematic review and meta-analysis on the association between BDNF val(66)met and hippocampal volume-a genuine effect or a winners curse? Am. J. Med. Genet. B Neuropsychiatr. Genet. 159B, 731-740 (2012).

27 Weickert, C. S., Hyde, T. M., Lipska, B. K., Herman, M. M., Weinberger, D. R. \& Kleinman, J. E. Reduced brain-derived neurotrophic factor in prefrontal cortex of patients with schizophrenia. Mol. Psychiatry 8, 592-610 (2003).

28 Weickert, C. S., Ligons, D. L., Romanczyk, T., Ungaro, G., Hyde, T. M., Herman, M. M. et al. Reductions in neurotrophin receptor mRNAs in the prefrontal cortex of patients with schizophrenia. Mol. Psychiatry 10, 637-650 (2005).

29 Hashimoto, T., Bergen, S. E., Nguyen, Q. L., Xu, B., Monteggia, L. M., Pierri, J. N. et al. Relationship of brain-derived neurotrophic factor and its receptor TrkB to altered inhibitory prefrontal circuitry in schizophrenia. J. Neurosci. 25, 372-383 (2005).

30 Wong, J., Hyde, T. M., Cassano, H. L., Deep-Soboslay, A., Kleinman, J. E. \& Weickert, C. S. Promoter specific alterations of brain-derived neurotrophic factor mRNA in schizophrenia. Neuroscience 169, 1071-1084 (2010).

31 Iritani, S., Niizato, K., Nawa, H., Ikeda, K. \& Emson, P. C. Immunohistochemical study of brain-derived neurotrophic factor and its receptor, TrkB, in the hippocampal formation of schizophrenic brains. Prog. Neuropsychopharmacol. Biol. Psychiatry 27, 801-807 (2003)

32 Takahashi, M., Shirakawa, O., Toyooka, K., Kitamura, N., Hashimoto, T., Maeda, K. et al. Abnormal expression of brain-derived neurotrophic factor and its receptor in the corticolimbic system of schizophrenic patients. Mol. Psychiatry 5, 293-300 (2000).

33 Durany, N., Michel, T., ZoÈchling, R., Boissl, K. W., Cruz-SaÂnchez, F. F., Riederer, P. et al. Brain-derived neurotrophic factor and neurotrophin 3 in schizophrenic psychoses. Schizophr. Res. 52, 79-86 (2001).

$34 \mathrm{Kim}$, H. W., Rapoport, S. I. \& Rao, J. S. Altered expression of apoptotic factors and synaptic markers in postmortem brain from bipolar disorder patients. Neurobiol. Dis. 37, 596-603 (2010)

35 Rao, J. S., Keleshian, V. L., Klein, S. \& Rapoport, S. I. Epigenetic modifications in frontal cortex from Alzheimer's disease and bipolar disorder patients. Transl. Psychiatry 2, e132 (2012).

36 Thompson Ray, M., Weickert, C. S., Wyatt, E. \& Webster, M. J. Decreased BDNF, trkB-TK + and GAD67 mRNA expression in the hippocampus of individuals with schizophrenia and mood disorders. J. Psychiatry Neurosci. 36, 195-203 (2011).

37 Sen, S., Duman, R. \& Sanacora, G. Serum brain-derived neurotrophic factor depression, and antidepressant medications: meta-analyses and implications. Biol. Psychiatry 64, 527-532 (2008)

38 Brunoni, A. R., Lopes, M. \& Fregni, F. A systematic review and meta-analysis of clinical studies on major depression and BDNF levels: implications for the role of neuroplasticity in depression. Int. J. Neuropsychopharmacol. 11, 1169-1180 (2008).

39 Teche, S. P., Nuernberg, G. L., Sordi, A. O., de Souza, L. H., Remy, L., Cereser, K. M. et al. Measurement methods of BDNF levels in major depression: a qualitative systematic review of clinical trials. Psychiatr. Q. (e-pub ahead of print 7 April 2013; doi 10.1007/s11126-013-9261-7).
40 Favalli, G., Li, J., Belmonte-de-Abreu, P., Wong, A. H. \& Daskalakis, Z. J. The role of BDNF in the pathophysiology and treatment of schizophrenia. J. Psychiatr. Res. 46, 1-11 (2012).

41 Green, M. J., Matheson, S. L., Shepherd, A., Weickert, C. S. \& Carr, V. J. Brain-derived neurotrophic factor levels in schizophrenia: a systematic review with meta-analysis. Mol. Psychiatry 16, 960-972 (2011).

42 Chen, W. G., Chang, Q., Lin, Y., Meissner, A., West, A. E., Griffith, E. C. et al. Derepression of BDNF transcription involves calcium-dependent phosphorylation of MeCP2. Science 302, 885-889 (2003).

43 Martinowich, K., Hattori, D., Wu, H., Fouse, S., He, F., Hu, Y. et al. DNA methylationrelated chromatin remodeling in activity-dependent BDNF gene regulation. Science 302, 890-893 (2003).

44 Levenson, J. M. Evidence that DNA (cytosine-5) methyltransferase regulates synaptic plasticity in the hippocampus. J. Biol. Chem. 281, 15763-15773 (2006).

45 Sharma, R. P., Tun, N. \& Grayson, D. R. DNA methylation changes in schizophrenia and bipolar disorder. Epigenetics. 3, 74-80 (2008).

46 Ishimaru, N., Fukuchi, M., Hirai, A., Chiba, Y., Tamura, T., Takahashi, N. et al. Differential epigenetic regulation of BDNF and NT-3 genes by trichostatin A and 5-aza$2^{\prime}$-deoxycytidine in Neuro-2a cells. Biochem. Biophys. Res. Commun. 394, 173-177 (2010).

47 Lubin, F. D., Roth, T. L. \& Sweatt, J. D. Epigenetic regulation of BDNF gene transcription in the consolidation of fear memory. J. Neurosci. 28, 10576-10586 (2008).

48 Molteni, R., Cattaneo, A., Calabrese, F., Macchi, F., Olivier, J. D. A., Racagni, G. et al. Reduced function of the serotonin transporter is associated with decreased expression of BDNF in rodents as well as in humans. Neurobiol. Dis. 37, 747-755 (2010).

49 Yu, Y., Zhang, H., Byerly, M. S., Bacon, L. D., Porter, T. E., Liu, G. E. et al. Alternative splicing variants and DNA methylation status of BDNF in inbred chicken lines. Brain. Res. 1269, 1-10 (2009).

50 Rutten, B. P. \& Mill, J. Epigenetic mediation of environmental influences in major psychotic disorders. Schizophr. Bull. 35, 1045-1056 (2009).

51 Karpova, N. N., Rantamäki, T., Di Lieto, A., Lindemann, L., Hoener, M. C. \& Castrén, E. Darkness reduces BDNF expression in the visual cortex and induces repressive chromatin remodeling at the BDNF gene in both hippocampus and visual cortex. Cell. Mol. Neurobiol. 30, 1117-1123 (2010).

52 Onishchenko, N., Karpova, N., Sabri, F., Castrn, E. \& Ceccatelli, S. Long-lasting depression-like behavior and epigenetic changes of BDNF gene expression induced by perinatal exposure to methylmercury. J. Neurochem. 106, 1378-1387 (2008).

53 Roth, T. L., Lubin, F. D., Funk, A. J. \& Sweatt, J. D. Lasting epigenetic influence of early-life adversity on the BDNF gene. Biol. Psychiatry 65, 760-769 (2009).

54 Roth, T. L., Zoladz, P. R., Sweatt, J. D. \& Diamond, D. M. Epigenetic modification of hippocampal Bdnf DNA in adult rats in an animal model of post-traumatic stress disorder. J. Psychiatr. Res. 45, 919-926 (2011).

55 Mill, J., Tang, T., Kaminsky, Z., Khare, T., Yazdanpanah, S., Bouchard, L. et al. Epigenomic profiling reveals DNA-methylation changes associated with major psychosis. Am. J. Hum. Genet. 82, 696-711 (2008).

56 Keleshian, V. L., Modi, H. R., Rapoport, S. I. \& Rao, J. S. Aging is associated with altered inflammatory, arachidonic acid cascade, and synaptic markers, influenced by epigenetic modifications, in the human frontal cortex. J. Neurochem. 125, 63-73 (2013).

57 Keller, S., Sarchiapone, M., Zarrilli, F., Videtic, A., Ferraro, A., Carli, V. et al. Increased BDNF promoter methylation in the Wernicke area of suicide subjects. Arch. Gen. Psychiatry 67, 258-267 (2010).

58 Keller, S., Sarchiapone, M., Zarrilli, F., Tomaiuolo, R., Carli, V., Angrisano, T. et al. TrkB gene expression and DNA methylation state in Wernicke area does not associate with suicidal behavior. J. Affect Disord. 135, 400-404 (2011).

59 Kordi-Tamandani, D. M., Sahranavard, R. \& Torkamanzehi, A. DNA methylation and expression profiles of the brain-derived neurotrophic factor (BDNF) and dopamine transporter (DAT1) genes in patients with schizophrenia. Mol. Biol. Rep. 39 10889-10893 (2012).

60 Fuchikami, M., Morinobu, S., Segawa, M., Okamoto, Y., Yamawaki, S., Ozaki, N. et al. DNA methylation profiles of the brain-derived neurotrophic factor (BDNF) gene as a potent diagnostic biomarker in major depression. PLoS One 6, e23881 (2011).

61 D'Addario, C., Dell'Osso, B., Galimberti, D., Palazzo, M. C., Benatti, B., Di Francesco, A. et al. Epigenetic modulation of BDNF gene in patients with major depressive disorder. Biol. Psychiatry 73, e6-e7 (2013).

62 D'Addario, C., Dell'Osso, B., Palazzo, M. C., Benatti, B., Lietti, L., Cattaneo, E. et al. Selective DNA methylation of BDNF promoter in bipolar disorder: differences among patients with BDI and BDII. Neuropsychopharmacology 37, 1647-1655 (2012).

63 Perroud, N., Salzmann, A., Prada, P., Nicastro, R., Hoeppli, M. E., Furrer, S. et al Response to psychotherapy in borderline personality disorder and methylation status of the BDNF gene. Transl. Psychiatry 3, e207 (2013).

64 Kim, J. M., Stewart, R, Kang, H. J., Kim, S. Y., Kim, S. W., Shin, I. S. et al. A longitudinal study of BDNF promoter methylation and genotype with poststroke depression. J. Affect. Disord. 1-7 (2013).

65 Toledo-Rodriguez, M., Lotfipour, S., Leonard, G., Perron, M., Richer, L., Veillette, S. et al. Maternal smoking during pregnancy is associated with epigenetic modifications of the brain-derived neurotrophic factor-6 exon in adolescent offspring. Am. J. Med. Genet $B$ Neuropsychiatr. Genet. 153B, 1350-1354 (2010).

66 Davies, M. N., Volta, M., Pidsley, R., Lunnon, K., Dixit, A., Lovestone, S. et al Functional annotation of the human brain methylome identifies tissue-specific epigenetic variation across brain and blood. Genome. Biol. 13, R43 (2012).

67 Unternaehrer, E., Luers, P., Mill, J., Dempster, E., Meyer, A. H., Staehli, S. et al. Dynamic changes in DNA methylation of stress-associated genes (OXTR, BDNF) after acute psychosocial stress. Transl. Psychiatry 2, e150 (2012). 